\title{
Research on the Teaching Practice of Inquiry Learning Based on the Design of Cultural and Creative Products of the Grand Canal
}

\author{
Yan $\mathrm{Gu}^{1} \mathrm{Li} \mathrm{Gu}^{2, *}$ \\ ${ }^{1}$ Department of Industrial Design, College of Mechanical Engineering, Jiangsu University of Science and Technology, \\ Zhenjiang, Jiangsu, China \\ ${ }^{2}$ College of Art and Design, Nanjing University of Technology, Nanjing, Jiangsu, China \\ *Corresponding author. Email: guli11111@163.com
}

\begin{abstract}
In the teaching practice, professional guidance teachers should guide students' research-oriented learning, explore scientific cultural and creative product development mode, constantly optimize the design, and learn advanced cultural concepts. In the teaching practice of cultural and creative product development, it is found that many students pay too much attention to the novel effect of cultural and creative product development due to the problems of concept and cognition of industrial design students, and do not pay enough attention to the cultural characteristics of cultural and creative products. Guiding students to apply the rich cultural content of the Grand Canal culture into the specific product design through teaching practice is conducive to the innovation of students' design thinking.
\end{abstract}

Keywords: Grand Canal culture, creative product design, research learning

\section{INTRODUCTION}

Compared with other majors, industrial design is a comprehensive application-oriented major. Industrial design education should have the characteristics of creativity, practicality, comprehensiveness and diversity, among which practicality is one of the important characteristics of modern industrial design education. Through practice teaching, students' ability of finding and solving problems, practical ability, comprehensive expression ability, practical work skills, communication and communication ability, team spirit and so on are cultivated. The innovative practice mode of research-based learning has achieved good teaching effect and is welcomed by students and teachers. From the actual professional practice, students have a better understanding of the development of the design industry, and students feel the difference between social needs and school knowledge, which makes up for the lack of school teaching. Through the research-based learning, innovation and practice, the teaching practice of industrial design has new ideas and ideas.

\section{TEACHING PRACTICE OF CULTURAL AND CREATIVE PRODUCTS}

\section{A. Positioning of cultural and creative products teaching practice in the Grand Canal}

Rousseau, an educator, believes that "education should be action rather than oral instruction." "Don't give all kinds of Oral Lessons to your students. Let them learn from experience." "Don't teach them knowledge like this or that, but let them discover it by themselves." We only advocate that our students learn from practice. ${ }^{1}$

In teaching practice, professional instructors should guide students to explore scientific cultural and creative product development mode, constantly optimize the design, and learn advanced cultural concepts. In guiding students to design cultural and creative products, industrial design teachers should advocate correct learning methods. Learning methods not only refer to specific learning strategies and methods, but also refer to the basic characteristics of learning in
Guochao Feng, France, Rousseau, Emile, China Society 
terms of autonomy, inquiry and cooperation. ${ }^{2}$ As a way of learning, research-based learning refers to learning in the cognitive way and psychological process similar to scientific research. We should also guide students to have a more in-depth understanding and cognition of the cultural background behind cultural and creative products, improve their cultural perception and understanding ability, and conduct research-based learning. In the process of cultural and creative product design, we should integrate relevant cognitive concepts into cultural and creative products, enhance the cultural heritage of cultural and creative products, and meet the development trend of modern cultural industry. Cultural and creative products rely on culture itself, which is the inheritance and development of culture. Through personalized and artistic design, cultural and creative products rely on cultural and creative products, so as to improve the communication effect of cultural and creative products. In the teaching practice of cultural and creative product development, it is found that many students pay too much attention to the novel effect of cultural and creative product development due to the problems of concept and cognition of industrial design students, and do not pay enough attention to the cultural characteristics of cultural and creative products.

Cultural and creative products should have their usability and practicability. They should not only stay in the fixed position of ornaments, but also be endowed with daily use. They can be seen everywhere and can be used easily, instead of being put on the shelf and nobody cares about them. In order to meet the needs of beauty, it is necessary to endow it with practicability as much as possible, and its consumers should be positioned as the general public.

- The price is suitable. A small part of them can adopt advanced customization, but the main body is ordinary money. Only in this way can we enter the daily life of the people;

- Mass production. Only in this way can we meet the needs of the public;

- Unique design. In order to establish its own brand and attract its users, we should take the local unique and distinctive cultural image and historical heritage as the main body;

- Design customization. We should fully consider the individual needs of consumers, so as to make their products more market.

i Ren, application of inquiry learning in senior high school English vocabulary teaching, foreign language teaching research of basic education, February 2008

\section{B. Analysis on design elements of cultural and creative products of Grand Canal}

With the advent of the modern Internet era, the aesthetic level and aesthetic taste of the public are constantly improving, and the requirements for cultural products are also higher and higher. In the process of cultural and creative product design, as a design professional college student, they should adhere to certain fashion concepts and principles. "Research based learning is to cultivate students with the attitude of never being satisfied, pursuing excellence, and the ability to ask and solve problems' as the basic goal, various problems and projects put forward by students in learning life and social life as the basic learning carrier, and the basic content is to obtain knowledge, experience and psychological experience in the whole process of raising and solving problems. It is a course with the basic teaching form of research-based learning by students themselves." ${ }^{3}$ In the design of cultural and creative products, it is necessary to train students to adopt research-based learning method for design practice, fully consider the aesthetic development needs of the public, and improve the fashion characteristics of cultural and creative products. In the process of traditional cultural and creative product development and design, many design college students stick to the traditional design concept and mode, and the product style designed is old and cannot meet the needs of the current social development, so it cannot meet the development needs of the current market. When designing cultural and creative products, students should be aware of this development trend, constantly optimize the design effect of cultural and creative products, and enhance the comprehensive development level of cultural and creative industries.

The cultural and creative products of the grand canal are to a large extent the epitome of the culture of the city where it is located. Therefore, when making cultural and creative products on the Grand Canal, while meeting the needs of consumers, they should also conform to the development purpose of the city, conform to the aesthetic standards of the public, and have certain educational significance and cultural heritage. Therefore, the cultural and creative products of the Grand Canal should be analyzed from the aspects of cultural elements, form elements, functional elements, material elements, packaging elements, etc.

1) Analysis of cultural elements: As a cultural and creative product, it has the characteristics of product and culture. In terms of product, cultural and creative products meet the material needs of consumers, while cultural products meet the spiritual needs of people. Generally speaking, cultural and creative products are

\footnotetext{
3 Chunli Zhang, nature and strategy of inquiry learning, Shandong educational research, August 2001
} 
the products that meet the aesthetic needs of modern people by reexamining the unique local cultural elements and designing them creatively, so that people can re understand these fading cultures. The memory of a place cannot be left in people's memory for a long time through one or two sightseeing tours. At this time, our cultural and creative products have the significance of their existence, which not only meets the needs of people's recall, that is, the spiritual level, but also the inheritance and continuation of culture. He said that the manifestation of cultural materialization. Therefore, in the design of canal cultural and creative products, we should deeply excavate the local historical and cultural elements, so as to inspire students to rely on historical culture and carry out design innovation again on canal cultural and creative products, so that students can learn and feel canal city culture through cultural and creative products, so that the canal culture can be inherited and continued.

Cultural elements are not only the rough printing and copying of cultural symbols, but also the discovery, analysis, selection, refinement, and finally the aesthetic design. Students are very interested in adding creativity to the design of cultural and creative products, adding the external characteristics of products with intuitive feelings and touching, and the cultural creativity of products can spread consumers' understanding of cultural connotation.

2) Analysis of morphological elements: Form elements include product shape, color matching, material selection, decoration and technology. It is the external expression of cultural and creative products and the external form that consumers can intuitively feel and touch. When guiding students in the design of canal cultural and creative products, students are required to have a deep understanding and research on the local canal city culture, grasp its historical value and aesthetics, analyze the form elements of cultural and creative products, and create the modeling beauty of cultural and creative products combined with the aesthetic standards and valuable culture of the new era.

3) Analysis of functional elements: Cultural and creative products are different from handicrafts and tourist souvenirs. They should not only consider the artistry and craftsmanship, but also pay attention to the practicality of products, that is, the use function of products. Canal cultural and creative products need to have practical function, cognitive function, aesthetic function and entertainment function. Practical function refers to the use value of a product in order to achieve a certain purpose; aesthetics is a subjective psychological activity process, which is a kind of public view of things according to their own taste. With the improvement of people's aesthetic level, it is necessary to design college students to do consumer's hobby investigation and research. Cultural and creative product design should pursue aesthetic form in design, pay attention to the display of aesthetic value, grasp the aesthetic needs of modern people, and give the public a sense of beauty through vision; entertainment function is one of the interesting product functions that the product should meet the needs of public entertainment under the fast pace of life and great pressure at present stage, which can release pressure to a certain extent.

4) Analysis of material elements: Cultural and creative products have various forms, and different materials will give people different feelings. In the material selection, we should also consider the process problems, reduce the cost as much as possible without affecting the quality, so as to be suitable for mass production and meet the market demand. It can also increase interactivity and enable consumers to integrate into it. Therefore, we will lead the students to visit the Shanghai Materials Museum to make them know all kinds of production materials.

5) Analysis of packaging elements: Compared with ordinary products, cultural and creative products have higher requirements in packaging. In terms of packaging, cultural heritage, additionality, environmental protection, regionality, humanization and sustainability should be taken into account. Good packaging can improve the cultural additionality, better spread culture, and a good packaging can bring great satisfaction to people's senses, which requires teachers to guide industry in teaching practice The students of design department carry out in-depth design to encourage students to establish their own original brand. Against the background of the rapid development of cultural industry, as a design professional teacher, students are required to first recognize the development trend of modern cultural and creative industry, combine with the aesthetic needs of the public, constantly innovate cultural and creative design, cultural and creative product design path, explore scientific design mode, and improve the cultural, artistic, fashion and practicality of cultural and creative products to meet the current cultural and creative industries The development trend of the industry. 


\section{RESEARCH AND GUIDANCE ON BRAND DESIGN OF CULTURAL AND CREATIVE PRODUCTS}

\section{A. Brand education of cultural and creative products}

Today's commodity competition is becoming more and more serious. Consumers' demand for commodities has gradually changed from unilateral material demand to diversified demand, which makes the design of brand image become a new competitive point. An excellent brand can bring a broader market, so the success of brand building is particularly important. First of all, students need to analyze the characteristics of excellent creative products about the Grand Canal culture.

1) Investigation and analysis of teachers' guidance to students' inquiry learning: Research based learning is a kind of teaching strategy. As a teaching strategy, "Research-based Learning" refers to a kind of teaching thought, teaching mode and teaching method that teachers complete the subject teaching task by initiating, promoting, supporting and guiding students' research-based learning activities. ${ }^{4}$

This kind of teaching strategy can be referred to as "research teaching strategy", while the teaching of implementing research-based teaching strategy can be called "research teaching". This is a brand-new teaching strategy, which is produced by the teaching idea of quality education, especially the cultivation of students' innovative spirit and practical ability. In order to study the market recognition degree of the Grand Canal cultural product design, the teacher guides the students to investigate and study, and uses the correct research method to investigate in many aspects.

a) Consumer side: Students think about the design from the perspective of consumers, because the consumer's impression of a commodity, not only stays on the quality and price, but also on the brand. A good brand is easier to be recognized and trusted by consumers. To build a successful brand, we need to give meaning to its goods. Cultural and creative products add culture and creativity. They are no longer just a single commodity, but cultural and creative products with stories and resonance with consumers. Nowadays, brand is quality, brand is commitment.

b) Analysis of similar cultural and creative products: Relying on cultural product creativity to spread the Grand Canal culture is a sustainable development path, which can let the cultural memory of the grand canal be inherited in young people's lives. In recent years, many multi-media have vigorously promoted the Grand Canal culture and the inheritance

\footnotetext{
Sheng Wang, theory and practice of inquiry learning, Beijing Education Science Press, 2002:44
}

and protection of intangible cultural heritage in the canal cultural belt. However, the impression of cities along the Grand Canal to the public is that there are only spatial displacement changes and lack of distinct Ontological Differences and characteristics. The cultural and creative products with the theme of Grand Canal culture are still in a relatively slow and lagging state, and the innovative design of cultural and creative products is still in a relatively slow and lagging state There are still many problems.

Students analyze the advantages and disadvantages of similar cultural and creative products from multiple perspectives, including brand attraction, target users, sales strategy, packaging characteristics, etc. To analyze the disadvantages, it is necessary for design majors to better understand the market and improve their deficiencies in design.

c) SWOT analysis: It is divided into internal and external aspects. In terms of internal advantages, students need to think: what are the points of cultural and creative products to attract consumers? What strategies are used to reflect the advantages of cultural and creative products? How to occupy a larger market? What are the internal deficiencies? Can it attract most consumers? Or is it just a small part of the crowd? What are the problems that lack of technology and cannot be realized? In terms of external opportunities, we should pay attention to whether there are suitable new business opportunities and how to strengthen the market position of cultural and creative products? What national policies are helpful to the development of cultural and creative products? The external problem is whether the town government supports it? Can we meet the needs of consumers? What are the changes in competitors? So many problems need students to explore with research-based learning, which is worth the attention of design students.

\section{2) Brand image and sales strategy}

a) Drawing up brand plan of cultural and creative products: First of all, students need to make brand planning of cultural and creative products, and then determine the tasks of each stage and set goals. A complete plan includes ensuring that all brand related activities and communication can reflect, establish and be loyal to the core values and spirit of the brand.

b) Image positioning and design of cultural and creative products: The image positioning of cultural and creative products is mainly considered from the following aspects: the design concept of the product, the characteristics of the product itself and the unique cultural and spiritual connotation of the product. The above three points are closely related to the needs of consumers. The brand image of cultural and creative products is actually the interaction between brand 
image positioning and consumer demand. Design is not artistic creation. Design needs to be generated according to the needs of users and is objective, while artistic creation is subjective. Artistic creation can be separated from users and pursue the beauty of creativity [12]. It is very important to transform the above three points into design elements and apply them to brand identification design, packaging design and display design. Teachers should pay attention to the students in the design teaching practice.

c) Principles of brand design identification: Difference principle: it can make consumers better identify the brand; Practical principle: it can make the brand more easily accepted and remembered by consumers, and will not affect the recognition with the difference of existing place and material; Artistic principle: better meet the public's pursuit of beauty; The principle of the times: everything keeps pace with the times. If you want to develop, you must make progress. Only by keeping up with the pace of the times can we not be eliminated.

\section{B. Brand communication of cultural and creative products in the Grand Canal}

The brand communication of the Grande Canal's creative products can be combined with many channels, online and offline. Against the background of Internet plus, teachers should better use the internet tool to change the old word of mouth and walk at the forefront of development. In the teaching practice of cultural and creative product design, information technology can greatly improve the management efficiency. Through the integration and efficient utilization of modern cultural and creative information resources, it can further improve the work efficiency of cultural and creative design, meet the development needs of cultural and creative industry, and improve the comprehensive efficiency of cultural and creative product design. In the teaching practice of cultural product development, there are still some problems in the construction of information system of cultural and creative product design, such as low efficiency of information utilization and lack of information technology utilization and guarantee. In teaching practice, as a design major, students should recognize the direction of the development of modern cultural and creative products and integrate modern information technology. In the teaching practice of traditional cultural and creative product design, due to the lack of organic integration of cultural and creative product design and modern information technology system construction, many design majors still adhere to the traditional mode and path, which is not conducive to the improvement of the comprehensive design efficiency of cultural and creative products. As a design major, we should break through the barriers between the various links of cultural and creative product design, build a modern information technology design system, and improve the design efficiency. In the teaching practice of cultural and creative development and design, there will be many problems in the process of promoting and constructing the information technology system. We need to constantly open up thinking and actively innovate, so that information technology can really lead the development of traditional cultural and creative product design.

Designers need to refine cultural elements and form brand style. Cultural and creative products are widely sought after because of their unique cultural, aesthetic and practical features. With the progress of society, people's pursuit of spiritual level is gradually improved. They hope that life can be embellished by more rich design and creative products, pursue its deeper cultural nature and pay attention to spiritual enjoyment. A good brand is the organic integration of the core value, style and service system of an enterprise. It can make consumers have a more detailed understanding of the product. The advantages and disadvantages of a brand are very important to the first impression of consumers. A good brand will make people have the desire to buy, so as to understand it, and trust it.

To establish a good cultural and creative brand, media communication and cultural heritage are indispensable. Cultural and creative IP needs careful planning and in-depth understanding of media communication rules. Teachers should spread these excellent cultural content, constantly lead students to understand to harvest spiritual satisfaction, and then carry out art and cultural consumption, so as to achieve cultural heritage and brand communication. Students inherit traditional culture through ordinary and practical product design activities. Teachers need to guide students to determine the design scheme. The teacher inspires students to conduct a preliminary investigation and analysis of consumer demand, and then guides students to determine the design direction of stationery, household appliances and other cultural and creative products in Zhenjiang canal city. After the teacher's teaching guidance, students will produce a lot of design ideas, and draw a lot of sketches. After the research, the students finally selected a better design scheme to carry out detailed design and 3D modeling rendering.

\section{Case analysis of stationery design}

1) Design of "high mountain and flowing water" humidifier: Zhenjiang city is developed due to the canal, surrounded by mountains and water, known as the first river and mountain in the world. Lu Yong, a student, was instructed to design the "high mountains and flowing water" humidifier pen mountain, which was based on the famous "No.1 River and mountain in the world" and created it artistically. "Fig. 1" shows the 
design sketch of "pen mountain". The function of the product is pen mountain, which is used in the study room. The air humidification device is added to the traditional function of the product. The water vapor generated can keep the pen head moist for a long time, which is convenient to use and can be used for many purposes.

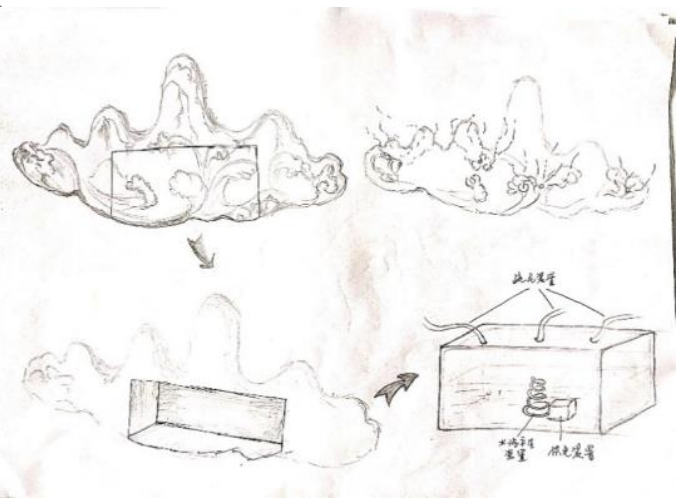

Fig. 1. The Design sketch of "pen mountain".

In terms of material selection, there are stone materials and synthetic resin. "Fig. 2" shows the material of "pen mountain ". Because of its convenient modeling and processing, synthetic resin can be mass produced and supplied to the general consumer market. Precious stone products can be used as high-quality products to carry out reasonable art publicity and attract consumers' attention.

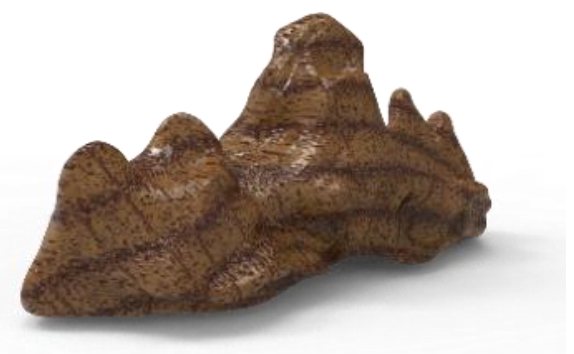

Fig. 2. The material of "pen mountain".

"Fig. 3" is the use effect of "pen mountain". Zhenjiang is a city with a strong cultural atmosphere. Its convenient waterway transportation and beautiful mountains and waters have attracted famous writers from all over the world, and they have left a strong mark in Zhenjiang. With the improvement of modern people's awareness of self-cultivation and the understanding and learning of traditional culture, the stationery has a great market. With the improvement of modern people's awareness of self-cultivation and the understanding and learning of traditional culture, the stationery has a great market. It is the unshirkable responsibility of Chinese civilization to give it new significance.

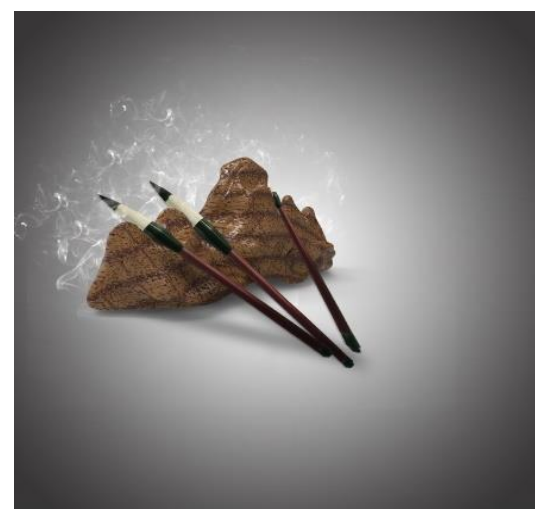

Fig. 3. The effect of "pen mountain".

\section{Overall design description}

The application of research-based learning practice enables students to understand the importance of "people-oriented", which makes people more convenient in the process of using, but not interesting in the function of using. It increases the interaction with users and makes the use experience better. It will become a product with great market prospects. The design of this study appliance reflects the peopleoriented design concept, through the change of the form to achieve different functions, but also in line with the needs of the times of canal culture development, this is an excellent design practice work of students.

\section{CONCLUSION}

The Grand Canal has accumulated rich cultural heritage in the cities along Jiangsu Province. The fundamental purpose of cultural and creative products of the Grand Canal is to promote and spread the local unique culture, material and intangible cultural heritage, and to bring potential possibilities for local economic development through cultural promotion. This requires teachers to guide students to systematically extract and sort out the most characteristic type elements in the Grand Canal cultural heritage. In the process of investigation, students will get the resonance and communication of local culture and culture of Zhenjiang city. Guiding students to apply the rich cultural content of the Grand Canal culture into the specific product design through teaching practice is conducive to the innovation of students' design thinking.

\section{References}

[1] Guochao Feng, France, Rousseau, Emile, China Society Press, 2000 
[2] Li Ren, application of inquiry learning in senior high school English vocabulary teaching, foreign language teaching research of basic education, February 2008

[3] Chunli Zhang, nature and strategy of inquiry learning, Shandong educational research, August 2001

[4] Sheng Wang, theory and practice of inquiry learning, Beijing Education Science Press, 2002:44

[5] Wenxin Chen. Annals of Chinese literature in Sui, Tang and Five Dynasties Volume I [M]. Hunan people's publishing house, 2003

[6] Peihong $\mathrm{Xu}$, Guangxin Zuo. Textual research on dantujian County in ancient city [M]. Jiangsu local records, 2001

[7] Hongen Pan. Research on the protection and utilization of the cultural heritage in the river section of the Beijing Hangzhou Dayun River [J]. Journal of Huaiyin Normal University, 2014

[8] Zhaojing Zheng. History of water conservancy in China [M]. Beijing: Commercial Press, 1998

[9] Yang Hong, Chun Xie. General annals of water transport [M]. Beijing: Local Records publishing house, 2003

[10] Jiaqi Yu. Historical investigation of Zhenjiang canal culture [J]. Journal of Zhenjiang University, 2018

[11] Zheng Wei. Sui Shu (Volume 3) [M]. Beijing: Zhonghua publishing house, 1973

[12] Xiaofeng Jiang. Research on cultural and creative product design of Museum System Based on regional culture [D]. Master's thesis of Hefei University of technology. 2017

[13] Yao Zhang. Research on the development and design of cultural and creative products based on museum resources [D]. Master's thesis of Suzhou University. 2015

[14] Feng Zhou, Wang Yangzi. Design and development strategy of cultural and creative commodity brand [J]. Design, 2017

[15] haoshu Jiang. How cultural resources make cultural industry [J]. Business culture, 2017

[16] Shaojun Bei. History and future of the Grand Canal [J]. China Maritime, 2012

[17] Yuqing Zou. Research on the design of cultural and creative products in Jiangsu small cities along the Grand Canal $[\mathrm{J}]$. Education and teaching forum, 2017

[18] Wenting Shi. Cultural relic protection at Danjiangkou is included in the Middle Route Project of South to North Water Diversion [J]. Hubei Yearbook, 2003

[19] Jixiang Shan. On the protection of large linear cultural heritage: breakthrough and pressure [J]. Southern cultural relics, 2003

[20] Chengcheng Liu. Observation on the development of cultural and creative parks in Taiwan [n]. China culture daily, 2015

[21] Yupeng Wang, Gao Yuanjie. Urban flood and flood control strategies in the canal region of Shandong in the Ming and Qing Dynasties [J]. Journal of Liaocheng University (SOCIAL SCIENCE EDITION), 2017 